\title{
Social information use for spatial decision in
}

\section{Zootoca vivipara}

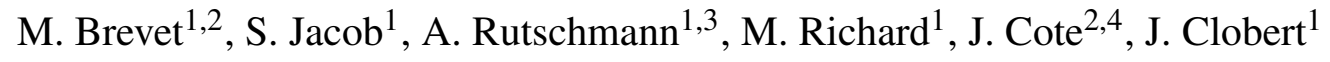 \\ ${ }^{1}$ Station d'Ecologie Théorique et Expérimentale (SETE), UMR5321, CNRS, 09200, Moulis, FR \\ ${ }^{2}$ Université Toulouse III Paul Sabatier, 31062, Toulouse, FR \\ ${ }^{3}$ School of Biological Sciences, University of Auckland, Auckland, NZ \\ ${ }^{4}$ Laboratoire Evolution et Diversité Biologique (EDB), UMR5174, CNRS, 31062, Toulouse, FR
}

Corresponding author: Mathieu Brevet. E-mail: brevetmathieu@ gmail.com 
Movements of individuals are conditioned by information acquisition coming from either personal or social sources. Yet, little is known about the processes used by individuals to make movement decisions when facing multiple sources of social information simultaneously. This study aimed to test experimentally how social information from multiple sources is used to make movement decisions, and whether a contrast in this information allows individuals to orientate in space. We used common lizards (Zootoca vivipara) in a replicated experimental setting: one focal individual received information from two other individuals coming from peripheral environments, before being given the opportunity to relocate in one or another of the peripheral environments. Our analyses revealed that the behavior of informants, their mother's morphology, as well as the quality of informants' environment, affected movement decisions: the probability to relocate from the focal area increased when informants displayed traits associated with low resources (no food intake, poor maternal condition) or high competition (high activity). The physical condition of individuals also mediated the use of social information about food intake, with a match between resource availability in informants and personal condition. Conversely, spatial orientation was not affected by the contrast of phenotype between informants nor by spatial variability in resource availability. This study highlights that multiple social information sources can be used for movement decisions, likely because these information sources reflect the quality of the surrounding environment (e.g., competition level or resources availability). It also emphasizes that social information use for movement is conditioned by individual phenotype. Information transfer, Information use 


\section{Introduction}

26 Information acquisition is central for an individual to assess the quality of its environment

27 and to take appropriate decisions to feed, survive and reproduce (Dall et al. 2005, Schmidt et

28 al. 2010). Information can either be obtained via personal interactions with the environment

29 (i.e., personal information, Dall et al. 2005) or via social interactions (i.e., social information,

30 Dall et al. 2005, Schmidt et al. 2010). Social information is acquired through the observa-

31 tion of conspecific's or heterospecific's detectable traits (e.g., behavior, performance, body

32 condition, odors; Moreira et al. 2008, Clobert et al. 2009) and can inform individuals about

33 both abiotic and biotic characteristics of the local and distant environments such as breeding

34 habitat quality (Doligez et al. 2002 and 2004) or conspecific density and resource availability

35 (Endriss et al. 2018). Social information can be intentionally transmitted by informant indi-

36 viduals through signals such as calls or territorial marking (Johnson 1973, Macedonia et al.

37 1993) but may also be inadvertently conveyed by cues (Schmidt et al, 2010), as it is the case

38 for breeding habitat quality, informed by reproduction performances in some bird species

39 (Doligez et al. 2002, 2004).

40 Social information has long been recognized to be key in organisms' decisions to move

41 through their environment and is notably known to influence the optimization of spatial deci-

42 sion making for microhabitat use (e.g., Moreira et al. 2008), habitat selection (Doligez et al.

43 2002, 2004) or dispersal (Cote and Clobert 2007, Jacob et al. 2015). In spatially heteroge-

44 neous environments, social information is expected to be especially useful for any movement

45 decision. Indeed, in such environments, the social information is made of a mosaic of cues

46 or signals carried by either local inhabitants or immigrants, respectively informing on the

47 specificities of close and distant habitats (Cote and Clobert 2007, Jacob et al. 2015). With

48 increasing heterogeneity, environmental predictability is expected to decrease and socially ac-

49 quired information can increase an individual knowledge of the general environment, hence

50 reducing the probability of erroneous decisions due to environmental uncertainty (Dall et al. 
51 2005, Riotte-Lambert et al. 2020). In other words, informed individuals are more likely to

52 make the right movement decisions (i.e., the one that maximizes their fitness) if they acquire

53 knowledge about the suitability of surrounding habitats throughout social information, com-

54 pared to when relying on their local prospects only, especially if their movement abilities are

55 restricted.

56 Yet, little is known about the use of social information for movements decision when multi-

57 ple sources of social information are simultaneously accessible to an individual (i.e., multiple

58 conspecifics reflecting different surrounding habitats). More specifically, two important ques-

59 tions have to be addressed. First, when multiple sources of information are available, how

60 information sources are used to decide whether the individual should relocate or not? One

61 may expect that the averaged information on surrounding habitats should prevail (Hyp. 1.a:

62 Social information synthesis, figure 1): an individual would optimize its movement by syn-

63 thesizing all sources of information available (i.e., each social cue or signal among sources),

64 whatever the quality and origin of the cue or signal, to get a global idea of the amount of

65 resource and level of intraspecific competition in the vicinity (Stamps 2001, Clobert et al.

66 2004, Bowler and Benton 2005). The use of information on surrounding habitats could also

67 depend on the phenotype of the informed individual, which would adjust movement decision

68 to its condition and relocate only when necessary (Hyp. 1.b: Phenotypic-dependent social

69 information synthesis, figure 1). Many examples in the literature illustrate such phenotype-

70 dependent use of social information, with dependence on personality (Smit and van Oers

71 2019, Morinay et al. 2020), age and success (Parejo et al. 2007), or body condition (Cote

72 and Clobert 2007). One may also expect individuals to use the contrast between available

73 information sources (Hyp 1.c: Contrasted social information use, figure 1): by comparing

74 the concordance or discordance of social cues or signals between sources, individuals might

75 be able to assess information reliability or environmental variability in the vicinity. The im-

76 portance of conflictual information for movement decisions has already been observed for 
77 conflicts between personal and social information (e.g., Cronin 2013, Winandy et al. 2020),

78 with prioritization of personal information in case of conflicts (Kendal 2009).

79 The second question lies in the spatial integration of information gathered from multiple

80 sources coming from different locations: how does an individual use multiple sources of in-

81 formation to orientate, and therefore to choose a specific destination of relocation between

82 alternative habitats? One likely hypothesis (Hyp. 2: Spatially contrasted social information

83 use, figure 1) is that differences in information between multiple sources originating from

84 different habitats allow spatial orientation for the information receivers. Such differences in

85 information could indeed inform the individual on the direction of habitats with a higher fit-

86 ness expectancy, since the surrounding habitats are possibly associated with different social

87 information quality as a function of their fitness expectancy (Schmidt et al. 2010).

88 To investigate these questions, we used the common lizard (Zootoca vivipara, Jacquin 1787)

89 as a model species. This lizard is known to use social information in different contexts, and

90 notably to acquire information about the dispersal status of conspecifics (Aragon 2006 b.),

91 the reproductive strategy and aggressiveness of other females from their ventral coloration

92 (Vercken et al. 2012), or the population density in the surrounding habitats through immi-

93 grants (Cote and Clobert 2007, Cote et al. 2008 a.). In this species, the use of personal and

94 social information is also known to occur immediately after birth and to shape natal dispersal

95 decisions (Clobert et al. 2012, Cote and Clobert 2012).

96 Here, we tested how common lizards use social information from two contrasted habitats,

97 varying in food availability (present or not), to take decisions of relocation from their local

98 area. We also tested whether such information could influence movements' orientation when

99 relocation occurred. To do so, we placed juvenile lizards (neonates from 2 to 4 days, born

100 in our facilities from caught gravid females) in a three-chamber system (figure S1), where

101 an information receiver (referred to as the focal individual further on) was confronted with

102 two individuals coming from independent chambers and carrying contrasting information (re- 
103 ferred to as informants further on). One informant came from an experimental environment

104 where food was provided, while the other came from an experimental environment where

105 food was absent. We generated all possible combinations of informants' sexes introduced to

106 the focal individual and measured multiple phenotypic traits that might convey information

107 about informants and their habitats. We hypothesized that informants could transmit social

108 information through their phenotype (e.g., behaviors, feeding, age, sex, or morphology) but

109 also through their mothers' condition (i.e., maternal effects, Bernardo 1996). These pheno-

110 typic traits are known to be related with short term sexual and resource competition contexts

111 (Massot 1992, Léna et al. 1998, Galliard et al. 2005 a. for sex and morphology; Lecomte

112 1994, Cote et al. 2008 a. for behaviors), or with the long-term environmental context through

113 maternal condition effects (Sorci and Clobert 1997, Uller and Olsson 2005, Mugabo et al.

114 2011). Note here that these phenotypic traits do not only inform about the competition in the

115 standardized experimental setup, but possibly also about the competition level present in the

116 habitat of origin of the individuals.

117 We expected relocation of the focal individual to vary with its phenotypic traits (Phenotype-

118 dependence of movement) as already shown for body condition (Cote and Clobert 2007), sex

119 (Galliard et al. 2005 a., Aragon et al. 2006 b.), age (Massot 1992, Léna et al. 1998), behaviors

120 (Cote et al. 2010) or maternal body condition (kin competition, Léna et al. 1998, Meylan et al.

121 2002). Using this set-up, we tested whether the focal individuals could use social information

122 from conspecifics to decide to relocate (or not) from their initial area. More specifically, we

123 expected focal individuals to increase their movements when information about high qual-

124 ity surrounding habitats is on average provided (Hyp. 1.a, figure 1): low competition for

125 resources (i.e., poorly active informants with poor physical conditions); long-term quality

126 of the habitat (i.e., informants' mothers with good physical conditions); low sexual compe-

127 tition (i.e., low male informants' number) or sufficient resources availability (i.e., well-fed

128 informants). The use of social information to adjust movement decisions might furthermore 
129 depend on the phenotype of focal individuals (Hyp. 1.b, figure 1), we specifically focused

130 here on the phenotype dependence of social information use about food availability. For in-

131 stance, we expected an increased probability of movements when focal individuals are in

132 low condition and provided with information about a high amount of resources, long-term

133 high habitat quality, or low competition in the vicinity. In contrast to average social informa-

134 tion, the contrast of traits between informants might reflect the heterogeneity of information

135 on surrounding environments (Hyp. 1.c, figure 1). Individuals might choose to decrease

136 their movements when heterogeneity of information about surrounding environments, and

137 thus possibly information uncertainty, increases (Riotte-Lambert et al. 2020, e.g. Heinen

138 and Stephens, 2006). Finally, we expected focal individuals to adjust movement direction

139 depending on social information differences between sources (Hyp. 2, figure 1), possibly

140 moving towards the chamber of the informant having access to food, with a better physical

141 condition, displaying low competitive behaviors, or being of the opposite gender. 


\section{Materials \& Methods}

\section{Species and study sites}

145 Zootoca vivipara (Jacquin 1787) is a small size ground-living species in the Lacertidae fam-

146 ily. This widespread species spans Northern Europe and Asia and lives in heathlands, bogs,

147 and wet grasslands. Individuals used in this study have been sampled in seven populations

148 in the Massif Central mountain range (France). These sites range from $1000 \mathrm{~m}$ to $1500 \mathrm{~m}$ and

149 cover the diversity of possible habitats in this region (Rutschmann et al. 2016). In the Massif

150 Central, mating takes place just after individuals emerge from hibernation, between March

151 and April. Parturition usually occurs between late June and late July, depending on temper-

152 ature conditions (Rutschmann et al. 2016). In our sites the current mode of reproduction is

153 ovoviviparity and juveniles emerge from the egg within a few hours after parturition. Some

154 of the juveniles disperse from their natal site a few days after birth (Massot 1992).

\section{Capture and rearing condition}

156 The capture and rearing conditions have been validated by an ethical committee (DAP number

157 5897-2018070615164391-v3). Twenty pregnant females were captured at each site between

158 June 12th and 24th, in 2019. These females were brought to a field laboratory, where we

159 measured snout to vent length. Females were maintained in individual plastic terrariums

$160(18.5 \times 12 \times 11 \mathrm{~cm})$, containing a shelter made from two slots of a cardboard egg-box and a

$1612 \mathrm{~cm}$ substrate of sterilized soil (Massot and Clobert 2000). Terrariums were placed under an

162 incandescent bulb of $25 \mathrm{~W}$ providing light and heat for 6 hours a day to allow basking (from 9

163 a.m. to 12 p.m. and from 2 p.m. to 5 p.m.). Terrariums were sprayed with water three times

164 a day. Females were fed with three mealworms, every second day.

165 After parturition (between July 2nd and 24th), neonates from a same clutch were isolated

166 from their mother in a terrarium (day 0). Females that just gave birth were immediately 
167 weighed. Neonates' snout to vent length (SVL) and body mass (BM) were measured the

168 day after their birth (day 1), before any feeding treatment. Sex was assessed following the

169 Lecomte et al. 1992 method. The same day, neonates were isolated to individual terrariums

$170(25 \times 15 \times 15 \mathrm{~cm})$, containing a shelter made from two slots of a cardboard egg-box and

171 layered with two sheets of absorbent paper. Juveniles were left for another day (day 2) in

172 their respective terrarium before experiments started on day 3, so they could consider this

173 terrarium as their living area (Aragon et al. 2006 b.). All juveniles and mothers were fed and

174 released at the mother's capture site on day 4.

\section{Experimental design}

176 The experiment aimed at testing if the spatial decisions of a focal individual were influenced

177 by informants' phenotypes and food intake. Each of the 56 replicates of the experiment re-

178 quired three juveniles (two informants and one focal individual). Each juvenile was tested in

179 a single replicate. For each replicate, juveniles were selected among clutches of mothers from

180 the same capture site. When possible, informants had the same laying date. Most experimen-

181 tal replicates $(n=37)$ took place 3 days after the birth of focal individuals but some replicates

182 happened 2- $(n=10)$ or 4-days $(n=9)$ after birth when there were too few births on the same

183 day. Similarly, $2(\mathrm{n}=10)$ and 4 days old $(\mathrm{n}=13)$ informants were used when necessary. Sev-

184 enteen replicates were associated with a difference of age between the focal individual and at

185 least one of the informants. When possible, the three individuals were selected from different

186 broods, but informants from the same brood were used in the same experimental replicate

187 when there were too few births $(n=19)$.

188 One day before the confrontation between individuals, one of the two informants had access

189 to food: three small crickets, from 3 to $5 \mathrm{~mm}$, were introduced in the terrarium. The number

190 of consumed crickets ( 0 to 3 ) was counted just before the experiment (referred to as the fed

191 informant's food intake further on). The focal individual was never fed before the experiment. 
192 Our experiment further manipulated the combination of informants' sexes orthogonally to the

193 information about food access. Each focal female $(n=29)$ or male $(n=27)$ was confronted with

194 two informant males, two informant females, or one informant male and one informant fe-

195 male. These combinations were balanced between replicates within an experimental day. In

196 the replicates with one informant male and one informant female, the fed informant was the

197 male in nearly half of the replicates $(n=14)$ and the female in the other replicates $(n=16)$.

198 Furthermore, the three juveniles had variable phenotypes (SVL and BM, mothers' SVL and

$199 \mathrm{BM}$ ) that we did not control for in the preparation of our experiments. However, we analyzed

200 their effects on movement decisions, since they displayed sufficient variability to be potential

201 social cues (informants SVL: $20 \pm 1 \mathrm{~mm}$, informants BM: $157.7 \pm 18.2 \mathrm{mg}$, informants'

202 mothers SVL: $62.2 \pm 4.1 \mathrm{~mm}$, informants' mothers BM: $3616 \pm 566.7 \mathrm{mg}$ ).

203 Replicates took place from July 5 th to 27 th between 7 a.m. and 8 p.m. We summed up the

204 timing of experiments in a categorical variable, accounting for the lighting periods in the field

205 laboratory, with four classes: early morning (7 a.m. to 9 a.m., n=13), morning (10 a.m. to 12

206 a.m, n=23), afternoon ( 1 p.m. to 4 p.m, n=13) and evening ( 5 p.m to 8 p.m, n=7).

207 By-products of experimental constraint (age difference between informants, informant kin-

208 ship and time windows) had no significant effect on relocation probability when individually

209 added in the selected model about relocation probability (respectively $(\mathrm{z}$-value, $\mathrm{p})=(-1.08$,

$2100.28) /(-0.85,0.39) /($ from 0.26 to 1.22 , from 0.22 to 0.80$)$ ). Difference in age between infor-

211 mants did not impact movement decision when added in the model about movement direction

$212\left(\chi^{2}=1.39, \mathrm{p}=0.24\right)$.

\section{Experimental assay}

214 The home terrarium of the focal individual was placed on an isolated table. Corridors (PVC

215 tubes of $25 \mathrm{~cm}$ length and $16 \mathrm{~mm}$ internal diameter) were introduced at each side of this terrar-

216 ium. Informants were placed in corridors' extremities and their arrival in the focal terrarium 
217 was synchronized by slightly brushing their tails (figure S1). We alternated the introduction

218 position (left or right) of the fed informant and males and females between each replicate so

219 that the position was not biased towards a treatment or an informant's sex. Once the infor-

220 mants entered the focal terrarium, exits were plugged. The dimension of the focal terrarium

$221(25 \times 15 \times 15 \mathrm{~cm})$ was sufficient to accommodate the three juveniles together while allowing

222 them to avoid each other. The three juveniles interacted together for thirty minutes (figure

223 S1). After that period, informants were put back in their respective terrariums. In the home

224 terrarium, absorbent paper, shelter, and heat/light source were removed to promote departure

225 (Aragon et al., 2006 b.). The focal individual was left five minutes in these conditions to

226 accommodate (figure S1). Then the corridors used previously were attached again at each ex-

227 tremity of the focal terrariums (without any modification since the informants' passage) and

228 connected to two identical and clean terrariums. The focal individual was left thirty minutes

229 in this system (figure S1). After this time, the experiment was stopped and we observed if 230 the focal individual had left his terrarium and in which direction. Terrariums in which focal

231 individuals arrived were washed with water between replicates. Corridors were used only

232 once. Experiments were entirely filmed with three webcams (Creative Live Camera Sync HD

233 720p) placed above each terrarium to analyze the three individuals' joint behaviors.

\section{Data analyses}

\section{Joint behaviors of focal and informant individuals}

236 Behaviors of focal and informant juveniles were measured to test their impact on relocation 237 decisions (Phenotype-dependence of movement and Hyp. 1.a, in figure S1). Due to technical 238 constraints (i.e., videos quality), we could not distinguish the behavior of informants and focal

239 individuals. As a consequence, we analyzed the joint behaviors of the three juveniles together 240 through the last twenty minutes of their confrontation, the first ten minutes being considered 
241 as an accommodation time (Cote et al. 2007, 2008 a.). We used BORIS software (Friard and

242 Gamba, 2016) to quantify the following behavioral traits (the description and interpretation

243 of behaviors are detailed in table 1): activity, sheltering, escaping attempt, boldness behav-

244 ior, non-aggressive proximity, competitive interactions, and tongue-flicking. These behaviors

245 were considered apart from other focal individuals' traits or informants' traits because they

246 described the behaviors of both focal and informant individuals simultaneously and cannot

247 individually be ascribed.

248 We synthesized behavioral information using a principal component analysis (PCA) (figure

249 S3; all analyses were performed with the "FactoMineR" R package, Lê et al. 2008). Given

250 the explained variance distribution (figure S2-A, computed from eigenvalues, with the same

251 distribution) we retained the first axis, explaining 50.4\% of the variance, for subsequent anal-

252 yses. This axis could be described as the global activity level, with non-negligible (loadings

$253>0.4$, variables close to this threshold were also displayed) positive contribution of activity,

254 competitive interactions, non-aggressive proximity and tongue-flicking behaviors, and a neg-

255 ative contribution of sheltering behavior (figure S2-B and table 2 for details). This axis will

256 be subsequently referred to as juveniles' joint activity level. The second PCA axis (which

257 mainly described the boldness behavior, figure S2-B) explained a non-negligible part of the

258 variance (18.5\%). Yet, when including this variable in our models we found no significant

259 effects of this variable on focal individuals' relocation ( $\mathrm{z}$-value $=-1.13, \mathrm{p}=0.26$ ) and it did

260 not change the other variables' significance.

\section{Condition of informants and focal individuals}

262 In our models, we considered three groups of variables describing informants' and focal indi263 viduals' condition (Table 2): the condition of focal individuals (age, SVL, BM, mother's SVL 264 and BM; testing for phenotype-dependence of movement and Hyp. 1.b in figure 1), the con265 dition of informants (mean age, mean SVL and BM, mean mothers' SVL and BM; testing for 
266 Hyp 1.a and Hyp 1.b in figure 1) and the absolute difference between informants' traits (SVL,

267 BM, mothers' SVL and BM; testing for Hyp 1.c in figure 1). Note that for the orientation

268 decision (see later), the latter group of variables was replaced by the raw difference between

269 informants' traits (SVL, BM, mothers' SVL and BM, left informant minus right informant

270 traits; testing for Hyp 2 in figure 1), to spatially polarize the contrast between informants.

271 To synthesize these variables we used a PCA and conserved the axes explaining most of the

272 variance in each group (all selected axes explained $>70 \%$ of the variance, figures S3-A, S4-

273 A, S5-A, and S6-A). All selected PCA axes and the respective part of explained variance are

274 described in table 2.

275 Briefly, the first two axes of the focal individual's condition PCA (figure S3-B) resume the 276 morphology (i.e., SVL and BM concomitant variations) of the focal individual's mother and

277 the focal individual's state (define as SVL, BM, and age concomitant variations). The first two

278 axes of the informants' condition PCA (figure S4-B) resume the morphology of informants'

279 mothers and informants' morphology. The first two axes of the contrasts in informants' con-

280 dition PCA (figure S5-B) resumed the contrast in the morphology of informants' mothers and

281 the contrast in informants' morphology. Finally, the first two axes of the PCA on differences

282 in informants' condition (figure S6-B) synthesized the difference in morphology of infor-

283 mants' mothers and difference in informants' morphology. In addition to these four PCAs

284 axes, we also considered in our models the focal individual's sex, informants' sex ratio, and

285 the fed informant's food intake. Of note, there was no correlation between the fed informant's

286 food intake and informants' morphology (Pearson correlation test, $\mathrm{p}=0.54$ ) or morphology

287 of informants' mothers (Pearson correlation test, $\mathrm{p}=0.48$ ), and between sex and physical

288 condition (Wilcoxon tests; focal individual's sex and state: $\mathrm{p}=0.47$, informants' sex-ratio

289 and morphology: $\mathrm{p}=0.42$ ). 


\section{Statistical Analyses}

291 All statistical analyses were performed with R software (R Development Core Team, 2008,

292 version 3.6.3). Graphs were produced using the package "ggplot2" (Wickham 2016).

293 First, we analyzed the relocation probability of focal individuals after their confrontation with

294 the two informants (Hyp. 1.a.b.c, figure 1). To do so, we used a Firth logistic regression (Firth

295 1993, 'brglm' function with a logit link, in "brglm” R package, Kosmidis and Firth 2021), a

296 penalized likelihood regression method. This method was chosen to take into account data

297 separation (Heinze and Schemper 2002), i.e. a predictor variable perfectly predicting the out-

298 come variable (Albert and Anderson 1984), and quasi-separated data, that is likely present in

299 our dataset given our sample size. We first tested for the population of origin as a potential

300 random effect (Zuur et al. 2009). Note here that a daily effect was partially nested in the pop-

301 ulation variable as the different capture sites are associated with different hatching periods

302 (Rutschmann et al., 2016) and as only one or two capture sites were used each day of ex-

303 periments. The population random effect appeared non-significant (analysis of deviance test

304 between null models with and without random effects, using standard logistic regressions; $\mathrm{p}=$

305 0.47) and was dropped in our subsequent models. Then, we performed a model selection (Ta-

306 ble S1) among the set of candidate variables, describing the informants and focal individual

307 joint behaviors (activity level PCA axis; to test for phenotype-dependence of movement and

308 Hyp. 1.a), the focal individual's condition (morphology of focal individuals' mothers and fo-

309 cal individuals' state PCA axes, and focal individuals' sex; to test for phenotype-dependence

310 of movement), informants' condition (morphology of informants' mothers and informants'

311 morphology PCA axes, informants' sex-ratio and the fed informant's food intake; to answer

312 Hyp. 1.a), contrasts in informants' condition (contrast in morphology of informants' mothers

313 and contrast in informants' morphology PCA axes; to test for Hyp. 1.c) and the interactions

314 between the fed informant's food intake and the focal individual condition variables (food

315 intake with every three focal individuals' condition variables; to test for Hyp. 1.b). All used 
316 quantitative variables were scaled. This model selection was performed using the function

317 'dredge' (package MuMIn, Barton et al. 2009). Only one model appeared in $\triangle A I C c<2$

318 (threshold for the best models; Burnham and Anderson 2004), this model was used for all

319 subsequent analyses.

320 The resulting model showed a sufficiently low variance inflation factor (maximal VIF of 1.71)

321 for the interpretation of our statistical results (O’brien 2007). We measured the quality of our

322 selected model by implementing a Nagelkerke pseudo-R-squared (Nagelkerke 1991). Effects

323 of retained variables were tested through Wald tests on the selected model variables (since

324 model comparison approach on Firth's regression still an on-going research, Kosmidis and

325 Firth 2021). We also used partial Nagelkerke pseudo-R-squared on our model to rank vari-

326 ables by their level of explained variance and relative importance obtained from the model

327 selection (sum of Akaike weights) to estimate all the variables' degree of importance (includ-

328 ing the ones that did not appear in our selected model).

329 A second analysis was conducted to test which of the informants' traits influenced the direc-

330 tion of relocation (Hyp. 2, figure 1) when focal individuals left their terrarium $(\mathrm{n}=22)$. This

331 time, we used simple logistic regressions with a binary response variable (leave toward left or

332 right). In this model, we used the spatial distribution of male and female informants (female

333 coming from the right and male coming from the left, male coming from the right and female

334 coming from the left or the same sex left and right), fed informant spatial origin (coming from

335 left or right), difference in informants' morphology (Table 2) and difference in morphology

336 of informants' mothers (Table 2). The model was diagnosed as presented before, with an

337 analysis of deviance instead of Wald tests for testing the variables effects (likelihood-ratio

338 tests, "car" R package, Fox and Weisberg 2018). Again, we obtained a sufficiently low VIF

339 (maximum equal to 1.38) for the interpretation of our results. 


\section{Results}

341 Over the 56 experimental replicates, 22 focal individuals left their terrariums. The regression 342 results revealed significant $(\mathrm{p}<0.05)$, or marginally significant $(0.05<\mathrm{p}<0.1)$, effects of focal

343 individuals' state (age, morphology) and sex, informants' traits (maternal morphology, the

344 fed informant's food intake), focal individuals' and informants' joint activity level, and the

345 interaction term between the focal individual's state and the fed informant's food intake. All

346 tests' statistics are available in Table 3. Shortly, the relocation probability of focal individuals

347 decreased with their age and increased with their morphology (figure S7-A) and was lower for

348 males compared to females (figure S7-B). The relocation probability further decreased with

349 larger informants' maternal morphology (figure S8-B, table 3) and the fed informant's food

350 intake (figure S8-A, table 3). Relocation also depended on the joint activity level of focal and

351 informant individuals (figure S9): it increased with the increase of activity, with higher levels

352 of social interaction (non-aggressive proximity and competitive interactions), and with higher

353 levels of exploration behaviors but decreased with increased sheltering behaviors (Mat\&Met,

354 figure S2-B and Table 2). We also found that the food intake of the fed informant interacted

355 with the phenotype of the focal individual to impact the focal individual's probability of re-

356 location (figure 2): relocation probability increased for an informant with poor food intake

357 confronted to a focal individual with a low score of individual's state (i.e. smaller morpho-

358 logical traits and older age) or for an informant with high food intake confronted to a focal

359 individual with a high score of individual's state (i.e. larger morphological traits and younger

360 age). Overall, the fitting quality of this model was good, with a Nagelkerke R-squared of

3610.68 .

362 We computed explained variance estimates for each variable included in the selected model

363 by using Nagelkerke's partial R-squared (Table 3). Food intake of fed informants and joint

364 behaviors had relatively high partial r-squared of 0.49 and 0.4 ; the sex of focal individuals

365 and morphology of informants' mothers had respective r-squared of 0.21 and 0.22 ; the state 
366 of focal individuals (age and morphology) had an r-squared of 0.13 . The r-squared of the

367 interaction between the fed informants' food intake and the focal individual's state (0.44)

368 was rather important relatively to the previously described values. The relative importance

369 of all tested variables (obtained from model selection, Table S1) showed that the importance

370 of the other non-selected variables was much lower (relative importance inferior to 0.27 for

371 non-selected variables and superior to 0.84 for selected variables).

372 We then analyzed the movement direction of the 22 focal individuals which left their terrari-

373 ums; nine individuals went to the right and thirteen to the left. No significant effect was found

374 among the tested variables, including the feeding treatment (Table 4, figure S10). Overall, we

375 obtained a Nagelkerke R-squared of 0.15 , suggesting a poor quality for the model. 


\section{Discussion}

377 We experimentally investigated how social information is used for movement decisions when

378 simultaneous sources of information (i.e., informant individuals), coming from different en-

379 vironments, are available for decision making.

380 We found the relocation probability of focal individuals to be phenotype-dependent (in sup-

381 port of the expected phenotype-dependence of movement): relocation was more likely to

382 occur for females, to decrease with individual's age, and to increase with their score of mor-

383 phology (SVL and BM). We also found that the relocation probability of focal individuals

384 increased when informants ate fewer available prey and originated from mothers with smaller

385 morphological traits (low BM and SVL), suggesting the use of averaged social information

386 for movement decisions (in support of Hyp. 1.a: figure 1). We further observed a phenotype-

387 dependence of the use of social information about food availability (in support of Hyp. 1.b:

388 figure 1). We found no significant influence of contrasts in traits between informants, poten-

389 tially representative of information variability or reliability, on the relocation probability of

390 focal individuals (contrary to the expectations from Hyp. 1.c: figure 1). Finally, when focal

391 individuals left their terrarium, the position of the informant having access to food did not

392 influence the direction of the movement, as for other differences in traits between informants

393 (contrary to the expectations from Hyp. 2: figure 1).

\section{Phenotype dependence of relocation}

395 In many species, movement from one location to another can be related to environmental fac-

396 tors or the individual's phenotype (respectively context- and phenotype-dependence, Bowler 397 and Benton, 2005). In the common lizard for example, dispersal is known to depend on the ju398 venile's phenotype such as its level of stress or its physical condition (Clobert et al., 2012). In 399 our experiments, we further observed that the focal individual's state variable correlated with 
400 the relocation probability: it increased with larger morphology (BM and SVL) and decreased 401 with age. The morphology of a neonate lizard, just after birth, directly reflects the amount 402 of energetic reserve available from initial yolk reserves in the egg and therefore influences 403 its performance in the early stage of life (Sinervo 1990, Olsson et al. 2002). As movements 404 implied energetic cost (for displacement itself or potential interactions with competitors and 405 predators, Bonte et al. 2012), larger reserves should provide an advantage for successfully re406 locating toward another habitat if necessary. Such a relationship between juveniles' physical 407 condition and movements had already been observed in common lizards for natal dispersal 408 (Meylan et al. 2002). Similarly, in the absence of any food intake, neonates only rely on 409 the energetic reserves inherited from the eggs' yolk for early physiological performance. As 410 a consequence, younger individuals may be more inclined to allocate such reserves towards 411 relocation than older individuals, forced to conserve their energy for foraging. It could be 412 an advantage to rapidly use their natal reserves for displacement or exploration, especially 413 as early-stage appeared to be central for future survival (Mugabo et al. 2010, Massot and 414 Aragon, 2013). Another possible hypothesis to explain the increase of relocation probability 415 for younger juveniles is that individuals may try to escape competition with their mother and 416 sibling by relocating as soon as possible from their birth location (Galliard et al. 2003, Cote 417 et al. 2007, Cote and Clobert 2010). We also observed an effect of focal individuals' sex on 418 their relocation probability: the propensity for juveniles to relocate was higher for females 419 than for males. This is a surprising result as male-biased movements are often observed in 420 lizard species (e.g., Doughty et al. 1994, Schofield et al. 2012), including the common lizard 421 (Galliard et al. 2005 b.). Yet, this result echoes what has been found in earlier experiments 422 (Aragon et al. 2006 b.), where, when relocating after a confrontation with another neonate, 423 female juveniles relocated with lower latency than males. Thus, it is likely that the observed 424 female-biased movement would have disappeared if we had let the juveniles dispersed for a 425 longer period, to potentially give way to male-biased movements. 
426 Finally, the positive effect of the joint level of activity of informants and focal individual on

427 the focal individual's relocation probability might result from independent or joint effects of

428 the focal individual behavior or of informants' competitiveness (that we will discuss later) that

429 we cannot distinguish in our experiment. When considering the focal individual's behavior,

430 a more active and explorative individual (high movement rate, low sheltering, high chemi-

431 cal exploration through tongue-flicking, high non-aggressive proximity with conspecifics) is

432 indeed more likely to leave its home environment (Cote et al. 2010).

\section{Use of social information from multiple sources}

434 In our experiment, interacting conspecifics might convey information about either the local

435 or the distant habitat. Although distinguishing between these two non-exclusive hypotheses

436 would require further experimental investigation that is beyond the scope of this paper, we

437 here elaborate on the patterns expected under each scenario and how they match (or not) with

438 our findings. If informants mainly carried information about the local habitat, we would ex-

439 pect focal individuals to stay in the current environments when confronting individuals bear-

440 ing cues or signals related to high-quality environments. On the contrary, a relocation of the

441 focal individual in presence of individuals carrying cues or signals related to high-quality en-

442 vironments would suggest that the phenotypic traits of informants convey information about

443 their habitat of origin.

444 We observed that relocation propensity increased when the morphology of informants' moth-

445 ers decreased, and when focal lizards were facing fed informants which did not eat much.

446 These observations are in favor of our second hypothesis as they are indicators of low re-

447 source availability in the close environment, and therefore related to an avoidance of a poor

448 local environment given the importance of resources for survival (Mugabo et al. 2010, 2011,

449 Massot and Aragon 2013). The physical condition of informants' mothers could also be

450 representative more broadly of habitat quality as it could vary with other important envi- 
451 ronmental parameters as density (Massot et al. 1992) or abiotic parameters as temperature

452 (Chamaillé-Jammes et al. 2006). Avoidance of informants whose mothers were of poor phys-

453 ical condition could then reflect the avoidance of a local environment of low quality. Such an

454 avoidance had already been observed with dispersal increase in case of too high competition

455 (Léna et al. 1998, Cote et al. 2008 a.) or abiotic parameter that does not match energetic re-

456 quirement (Bestion et al. 2015). We also observed that relocation propensity increased with

457 juveniles' (informants and focal individual) activity. More knowledge about the individual

458 behaviors of informants would have helped to refine our interpretations but the presence of

459 active and aggressive conspecifics is likely to reflect high levels of direct competition in the

460 local environment (Sih et al. 2004, e.g. Garland et al. 1990). A measure of stress hormones

461 (as corticosterone, see Belliure et al. 2004) would be useful to precise the influence of infor-

462 mants' stress level on focal individuals' relocation.

463 Finally, we also observed that relocation probability increased when the fed informant food

464 intake and the focal individual's physical condition were both low or both high. Again, this

465 result suggests that relocation preferentially occurs when local resource availability does not

466 match the focal individual phenotype. In the first case, individuals seemed to avoid a local

467 environment with insufficient resources given their conditions (low energetic reserves), while

468 in the second case, they seemed to escape unnecessary competition for resources while hav-

469 ing a good enough physical condition to relocate toward a less competitive habitat. Such

470 results further suggest that the use of social information is mediated by the phenotype of the

471 focal individuals, a dependency that has been already observed in previous studies (Cote and

472 Clobert 2007, Cote and Clobert 2010, but also Parejo et al. 2007 in other species) but never

473 with information on direct resources availability at stake. 


\section{On the meaning of informants' traits}

475 In our experiment, interacting conspecifics might convey information about either the local

476 or the distant habitat. Although distinguishing between these two non-exclusive hypotheses

477 would require further experimental investigation that is beyond the scope of this paper, we

478 here elaborate on the patterns expected under each scenario and how they match (or not) with

479 our findings. If informants mainly carried information about the local habitat, we would ex-

480 pect focal individuals to stay in the current environments when confronting individuals bear-

481 ing cues or signals related to high-quality environments. On the contrary, a relocation of the

482 focal individual in presence of individuals carrying cues or signals related to high-quality en-

483 vironments would suggest that the phenotypic traits of informants convey information about

484 their habitat of origin.

485 We observed that relocation propensity increased when the morphology of informants' moth-

486 ers decreased, and when focal lizards were facing fed informants which did not eat much.

487 These observations are in favor of our second hypothesis as they are indicators of low re-

488 source availability in the close environment, and therefore related to an avoidance of a poor

489 local environment given the importance of resources for survival (Mugabo et al. 2010, 2011,

490 Massot and Aragon 2013). The physical condition of informants' mothers could also be

491 representative more broadly of habitat quality as it could vary with other important envi-

492 ronmental parameters as density (Massot et al. 1992) or abiotic parameters as temperature

493 (Chamaillé-Jammes et al. 2006). Avoidance of informants whose mothers were of poor phys-

494 ical condition could then reflect the avoidance of a local environment of low quality. Such an

495 avoidance had already been observed with dispersal increase in case of too high competition

496 (Léna et al. 1998, Cote et al. 2008 a.) or abiotic parameter that does not match energetic

497 requirement (Bestion et al. 2015). Yet, we also observed that relocation propensity increased

498 with juveniles' (informants and focal individual) activity. More knowledge about the individ-

499 ual behaviors of informants would have helped to refine our interpretations but the presence 
500 of active and aggressive conspecifics is likely to reflect high levels of direct competition in

501 the local environment (Sih et al. 2004, e.g. Garland et al. 1990). A measure of stress hor-

502 mones (as corticosterone, see Belliure et al. 2004) would be useful to precise the influence of

503 informants' stress level on focal individuals' relocation.

504 Finally, we also observed that relocation probability increased when the fed informant food

505 intake and the focal individual's physical condition were both low or both high. Again, this

506 result suggests that relocation preferentially occurs when local resource availability does not

507 match the focal individual phenotype. In the first case, individuals seemed to avoid a local

508 environment with insufficient resources given their conditions (low energetic reserves), while

509 in the second case, they seemed to escape unnecessary competition for resources while hav-

510 ing a good enough physical condition to relocate toward a less competitive habitat. Such

511 results further suggest that the use of social information is mediated by the phenotype of the

512 focal individuals, a phenotype dependence of social information use that has been observed

513 previously (Cote and Clobert 2007, Cote and Clobert 2010, but also Parejo et al. 2007 in

514 other species) but never with information on direct resources availability at stake.

\section{Direction of movement}

516 Previous findings have shown a limited but existing ability to orientate in space for the com-

517 mon lizard (Strijbosch et al, 1983). Here, we found no effect of the difference in food access

518 between informants or other observed contrasts between informants on movement orientation

519 when relocation occurred. Given the small sample size for direction analyses (22 replicates),

520 we have to be very cautious about the validity of such effects. These results might suggest that

521 focal individuals considered social cues or signals from present information sources as infor-

522 mation about local conditions, for which no orientation is needed. Alternatively, individuals

523 might not have had access to sufficient cues for visual orientation, the design being symmet-

524 rical and the arrival lasting few seconds only. Decisions on direction would then mainly rely 
525 on informants' arrival with olfactory signals or cues left by informants in corridors (Aragon

526 et al. 2006 a. and c.). Further experiments, focusing for example on pheromones carried by

527 informants, would be necessary to make any conclusion on the actual use of these odors.

\section{Conclusion}

529 Our experiment showed that the averaged social information coming from multiple sources

530 was transmitted by interacting conspecifics, with mediation in the use of some information by

531 the phenotype of focal individuals. Yet, contrasts between information sources were not used

532 in our experiments for relocation decisions or orientation. The importance of these informa-

533 tion transfers for spatial use could be understood as surrounding habitat quality assessment,

534 with indication on resource availability and degree of intra-specific competition. We also 535 showed that, for the common lizard, information prioritization could occur, with a preference 536 over information related to the immediate environment.

\section{Author contribution}

$538 \mathrm{MB}, \mathrm{MR}, \mathrm{JC}, \mathrm{SJ}$ and AR designed the experiment. MB, JC and AR performed the field work.

539 MB performed all experiments and analyses. MB, MR, JC, SJ and AR wrote the manuscript.

\section{Funding}

541 This work was supported by the Agence Nationale de la Recherche (ANR-17-CE02-0013) 


\section{Acknowledgements}

543 We thank S. Liegeois, C. Fosse, A. Le Pajolec and C. Lauden for their help during experi-

544 ments and field work. We thank the Parc National des Cévennes for allowing us to use the

545 different sampled sites. This work beneficiated from the scientific environment of the Labo-

546 ratoire d'Excellence entitled TULIP (ANR-10-LABX-41). The 'Office Nationale des Forêts',

547 the 'Parc National des Cévennes', and the regions Auvergne, Rhône Alpes and Languedoc

548 Roussillon delivered permits to capture and handle lizards (permits 81-17 2013-05; 2013274-

549 0002, 2013/DREAL/259). No conflict of interest has to be declared.

\section{Data availability}

551 Analyses reported in this article can be reproduced using the data provided by Brevet et al.

552 (2021). 


\section{Bibliography}

554 Albert A, Anderson JA. 1984. On the existence of maximum likelihood estimates in logistic regression 555 models. Biometrika. 71(1):1-10.

556

557 Aragón P, Meylan S, Clobert J. 2006. Dispersal status-dependent response to the social environment 558 in the Common Lizard, Lacerta vivipara. Functional Ecology. 20(5):900-907.

560 Aragón P, Clobert J, Massot M. 2006. Individual dispersal status influences space use of conspe561 cific residents in the common lizard, Lacerta vivipara. Behav Ecol Sociobiol. 60(3):430-438.

563 Aragón P, Massot M, Gasparini J, Clobert J. 2006. Socially acquired information from chemical 564 cues in the common lizard, Lacerta vivipara. Animal Behaviour. 72(5):965-974.

566 Belliure J, Meylan S, Clobert J. 2004. Prenatal and postnatal effects of corticosterone on behavior 567 in juveniles of the common lizard, Lacerta vivipara. Journal of Experimental Zoology Part A: Com568 parative Experimental Biology. 301A(5):401-410.

570 Bernardo J. 1996. Maternal Effects in Animal Ecology. American Zoologist. 36(2):83-105.

572 Barton K. 2020. MuMIn: Multi-Model Inference. R package version 1.43.17.

574 Bestion E, Clobert J, Cote J. 2015. Dispersal response to climate change: scaling down to intraspecific 575 variation. Ecology Letters. 18(11):1226-1233.

577 Bonte D, Dyck HV, Bullock JM, Coulon A, Delgado M, Gibbs M, Lehouck V, Matthysen E, Mustin

578 K, Saastamoinen M, et al. 2012. Costs of dispersal. Biological Reviews. 87(2):290-312. 
580 Bowler DE, Benton TG. 2005. Causes and consequences of animal dispersal strategies: relating indi-

581 vidual behaviour to spatial dynamics. Biological Reviews. 80(2):205-225.

582

583 Burnham KP, Anderson DR. 2004. Multimodel Inference: Understanding AIC and BIC in Model

584 Selection. Sociological Methods \& Research. 33(2):261-304.

585

586 Chamaillé-Jammes S, Massot M, Aragón P, Clobert J. 2006. Global warming and positive fitness

587 response in mountain populations of common lizards Lacerta vivipara. Global Change Biology.

588 12(2):392-402.

589

590 Clobert J, Manuel Massot M, Galliard JFL. 2012. 3 - Multi-determinism in natal dispersal: the com-

591 mon lizard as a model system. In Clobert J, Baguette M, Benton TG, Bullock JM, editors. Dispersal

592 Ecology and Evolution. Oxford University Press. p. 29-40.

593

594 Clobert J, Ims RA, Rousset F. 2004. 13 - Causes, Mechanisms and Consequences of Dispersal. In:

595 Hanski I, Gaggiotti OE, editors. Ecology, Genetics and Evolution of Metapopulations. Burlington:

596 Academic Press. p. 307-335.

597

598 Clobert J, Galliard J-FL, Cote J, Meylan S, Massot M. 2009. Informed dispersal, heterogeneity in

599 animal dispersal syndromes and the dynamics of spatially structured populations. Ecology Letters.

600 12(3):197-209.

601

602 Cooper WE. 1994. Chemical discrimination by tongue-flicking in lizards: A review with hypothe-

603 ses on its origin and its ecological and phylogenetic relationships. J Chem Ecol. 20(2):439-487.

604

605 Cote Julien, Boudsocq S, Clobert J. 2008. Density, social information, and space use in the com-

606 mon lizard (Lacerta vivipara). Behav Ecol. 19(1):163-168.

607 
608 Cote J, Clobert J. 2007. Social information and emigration: lessons from immigrants. Ecology Let-

609 ters. 10(5):411-417.

610

611 Cote J, Clobert J. 2010. Risky dispersal: avoiding kin competition despite uncertainty. Ecology.

612 91(5):1485-1493.

613

614 Cote J, Clobert J, Brodin T, Fogarty S, Sih A. 2010. Personality-dependent dispersal: characteri-

615 zation, ontogeny and consequences for spatially structured populations. Philosophical Transactions of

616 the Royal Society of London B: Biological Sciences. 365(1560):4065-4076.

617

618 Cote J, Clobert J, Fitze PS. 2007. Mother-offspring competition promotes colonization success.

619 PNAS. 104(23):9703-9708.

620

621 Cote J., Dreiss A, Clobert J. 2008. Social personality trait and fitness. Proceedings of the Royal

622 Society of London B: Biological Sciences. 275(1653):2851-2858.

623

624 Cronin AL. 2013. Conditional Use of Social and Private Information Guides House-Hunting Ants.

625 PLOS ONE. 8(5):e64668.

626

627 Dall SRX, Giraldeau L-A, Olsson O, McNamara JM, Stephens DW. 2005. Information and its use

628 by animals in evolutionary ecology. Trends in Ecology \& Evolution. 20(4):187-193.

629

630 Doligez B, Danchin E, Clobert J. 2002. Public Information and Breeding Habitat Selection in a Wild

631 Bird Population. Science. 297(5584):1168-1170.

632

633 Doligez B, Pärt T, Danchin E, Clobert J, Gustafsson L. 2004. Availability and use of public infor-

634 mation and conspecific density for settlement decisions in the collared flycatcher. Journal of Animal

635 Ecology. 73(1):75-87. 
637 Doughty P, Sinervo B, Burghardt GM. 1994. Sex-biased dispersal in a polygynous lizard, Uta stans-

638 buriana. Animal Behaviour. 47(1):227-229.

639

640 Dubois F, Drullion D, Witte K. 2012. Social information use may lead to maladaptive decisions:

641 a game theoretic model. Behav Ecol. 23(1):225-231.

642

643 Endriss SB, Vahsen ML, Bitume EV, Monroe JG, Turner KG, Norton AP, Hufbauer RA. 2018. The

644 importance of growing up: juvenile environment influences dispersal of individuals and their neigh-

645 bours. Ecology Letters. 0(0).

646

647 Firth D. 1993. Bias Reduction of Maximum Likelihood Estimates. Biometrika. 80(1):27-38.

648

649 Fox J, Weisberg S. 2018. An R Companion to Applied Regression. SAGE Publications.

650

651 Friard O, Gamba M. 2016. BORIS: a free, versatile open-source event-logging software for video/audio

652 coding and live observations. Methods in Ecology and Evolution. 7(11):1325-1330.

653

654 Galliard J-FL, Ferrière R, Clobert J. 2005. Effect of patch occupancy on immigration in the com-

655 mon lizard. Journal of Animal Ecology. 74(2):241-249.

656

657 Galliard J-FL, Fitze PS, Ferrière R, Clobert J. 2005. Sex ratio bias, male aggression, and popula-

658 tion collapse in lizards. PNAS. 102(50):18231-18236.

659

660 Galliard J-FL, Ferrière, Clobert J. 2003. Mother-offspring interactions affect natal dispersal in a

661 lizard. Proceedings of the Royal Society of London B: Biological Sciences. 270(1520):1163-1169.

662

663 Garland T, Hankins E, Huey RB. 1990. Locomotor Capacity and Social Dominance in Male Lizards. 
664 Functional Ecology. 4(2):243-250.

665

666 Heinen VK, Stephens DW. 2016. Blue jays, Cyanocitta cristata, devalue social information in un-

667 certain environments. Animal Behaviour. 112:53-62.

668

669 Heinze G, Schemper M. 2002. A solution to the problem of separation in logistic regression. Statistics

670 in Medicine. 21(16):2409-2419.

671

672 Hurvich CM, Tsai C-L. 1993. A Corrected Akaike Information Criterion for Vector Autoregressive

673 Model Selection. Journal of Time Series Analysis. 14(3):271-279.

674

675 Jacob S, Chaine AS, Schtickzelle N, Huet M, Clobert J. 2015. Social information from immigrants:

676 multiple immigrant- based sources of information for dispersal decisions in a ciliate. Journal of Ani-

677 mal Ecology. 84(5):1373- 1383.

678

679 Johnson RP. 1973. Scent marking in mammals. Animal Behaviour. 21(3):521-535. Kendal R, Coolen

680 I, and Laland K. 2009. 13 - Adaptive trade-offs in the use of social and personal information. In Dukas

681 R, Ratcliffe JM, editors. Cognitive Ecology II. University of Chicago Press. p. 249-271.

682

683 Kosmidis I, Firth D. 2021. Jeffreys-prior penalty, finiteness and shrinkage in binomial-response gen-

684 eralized linear models. Biometrika. 108(1):71-82.

685

686 Lê S, Josse J, Husson F. 2008. FactoMineR: An R Package for Multivariate Analysis. Journal of

687 Statistical Software. 25(1):1-18.

688

689 Lecomte J, Clobert J, Massot M, Barbault R. 1994. Spatial and behavioural consequences of a density

690 manipulation in the common lizard1. Écoscience. 1(4):300-310.

691 
692 Léna J-P, Clobert J, de Fraipont M, Lecomte J, Guyot G. 1998. The relative influence of density

693 and kinship on dispersal in the common lizard. Behav Ecol. 9(5):500-507.

694

695 Macedonia JM, Evans CS. 1993. Essay on Contemporary Issues in Ethology: Variation among Mam-

696 malian Alarm Call Systems and the Problem of Meaning in Animal Signals. Ethology. 93(3):177-197.

697

698 Massot, Clobert. 2000. Processes at the origin of similarities in dispersal behaviour among siblings.

699 Journal of Evolutionary Biology. 13(4):707-719.

700

701 Massot M. 1992. Determinisme de la dispersion chez le lezard vivipare [Phd thesis]. Paris 11.

702

703 Massot M, Aragón P. 2013. Phenotypic Resonance from a Single Meal in an Insectivorous Lizard.

704 Current Biology. 23(14):1320-1323.

705

706 Massot M, Clobert J, Pilorge T, Lecomte J, Barbault R. 1992. Density Dependence in the Common

707 Lizard: Demographic Consequences of a Density Manipulation. Ecology. 73(5):1742-1756.

708

709 Massot M, Lecomte J, Clobert J. 1992. Sex identification in juveniles of Lacerta vivipara. Amphibia-

710 Reptilia. 13(1):21-25.

711

712 Meylan S, Belliure J, Clobert J, de Fraipont M. 2002. Stress and Body Condition as Prenatal and

713 Postnatal Determinants of Dispersal in the Common Lizard (Lacerta vivipara). Hormones and Behav714 ior. 42(3):319-326.

715

716 Moreira PL, López P, Martín J. 2008. Discrimination of conspecific faecal chemicals and spatial 717 decisions in juvenile Iberian rock lizards (Lacerta monticola). acta ethol. 11(1):26-33.

718

719 Morinay J, Forsman JT, Germain M, Doligez B. 2020. Behavioural traits modulate the use of het- 
720 erospecific social information for nest site selection: experimental evidence from a wild bird popula-

721 tion. Proceedings of the Royal Society B: Biological Sciences. 287(1925):20200265.

722

723 Mugabo M, Marquis O, Perret S, Galliard JFL. 2010. Immediate and delayed life history effects

724 caused by food deprivation early in life in a short-lived lizard. Journal of Evolutionary Biology. 725 23(9):1886-1898.

726

727 Mugabo M, Marquis O, Perret S, Le Galliard J-F. 2011. Direct and socially-mediated effects of food 728 availability late in life on life-history variation in a short-lived lizard. Oecologia. 166(4):949-960.

730 Nagelkerke NJD. 1991. A note on a general definition of the coefficient of determination. Biometrika.

731 78(3):691- 692.

732

733 Nally RM, Walsh CJ. 2004. Hierarchical Partitioning Public-domain Software. Biodiversity and Con-

734 servation. 13(3):659-660.

735

736 O’brien RM. 2007. A Caution Regarding Rules of Thumb for Variance Inflation Factors. Qual Quant. 737 41(5):673-690.

738

739 Olsson M, Wapstra E, Olofsson C. 2002. Offspring size-number strategies: Experimental manipu740 lation of offspring size in a viviparous lizard (Lacerta vivipara). Functional Ecology. 16:135-140.

742 Parejo D, White J, Danchin E. 2007. Settlement decisions in blue tits: difference in the use of so-

743 cial information according to age and individual success. Naturwissenschaften. 94(9):749-757.

745 R Core Team. 2020. R: A Language and Environment for Statistical Computing. R Foundation

746 for Statistical Computing, Vienna, Austria. 
748 Riotte-Lambert L, Matthiopoulos J. 2020. Environmental Predictability as a Cause and Consequence

749 of Animal Movement. Trends in Ecology \& Evolution.

750

751 Rutschmann A, Miles DB, Le Galliard J-F, Richard M, Moulherat S, Sinervo B, Clobert J. 2016.

752 Climate and habitat i nteract to shape the thermal reaction norms of breeding phenology across lizard

753 populations. J Anim Ecol. 85(2):457-466.

754

755 Schmidt KA, Dall SRX, Van Gils JA. 2010. The ecology of information: an overview on the eco-

756 logical significance of making informed decisions. Oikos. 119(2):304-316.

757

758 Schofield JA, Fenner AL, Pelgrim K, Bull CM, Schofield JA, Fenner AL, Pelgrim K, Bull CM.

759 2013. Male-biased movement in pygmy bluetongue lizards: implications for conservation. Wildl

760 Res. 39(8):677-684.

761

762 Seppänen J-T, Forsman JT, Mönkkönen M, Thomson RL. 2007. Social Information Use Is a Pro-

763 cess Across Time, Space, and Ecology, Reaching Heterospecifics. Ecology. 88(7):1622-1633.

764

765 Sih A, Bell A, Johnson JC. 2004. Behavioral syndromes: an ecological and evolutionary overview.

766 Trends in Ecology \& Evolution. 19(7):372-378.

767

768 Sinervo B. 1990. The Evolution of Maternal Investment in Lizards: An Experimental and Com-

769 parative Analysis of Egg Size and Its Effects on Offspring Performance. Evolution. 44(2):279-294.

770

771 Smit JAH, van Oers K. 2019. Personality types vary in their personal and social information use.

772 Animal Behaviour. 151:185-193.

773

774 Sorci G, Clobert J. 1997. Environmental maternal effects on locomotor performance in the com775 mon lizard (Lacerta vivipara). Evol Ecol. 11(5):531-541. 
777 Spencer WD. 2012. Home ranges and the value of spatial information. J Mammal. 93(4):929-947.

778

779 Stamps J. 2001. Habitat selection by dispersers: integrating proximate and ultimate approaches. p.

$780 \quad 230-242$.

781

782 Strijbosch H, Rooy PTJC van, Voesenek L a. CJ. 1983. Homing behaviour of Lacerta agilis and

783 Lacerta vivipara (Sauria, Lacertidae). Amphibia-Reptilia. 4(1):43-47.

785 Uller T, Olsson M. 2005. Trade-offs between offspring size and number in the lizard Lacerta vivipara:

786 a comparison between field and laboratory conditions. Journal of Zoology. 265(3):295-299.

787

788 Vercken E, Sinervo B, Clobert J. 2012. The importance of a good neighborhood: dispersal deci-

789 sions in juvenile common lizards are based on social environment. Behav Ecol. 23(5):1059-1067.

790

791 Wickham H. 2016. ggplot2: Elegant Graphics for Data Analysis. Springer-Verlag New York.

792

793 Winandy L, Di Gesu L, Lemoine M, Jacob S, Martin J, Ducamp C, Huet M, Legrand D, Cote J.

794 2021. Maternal and personal information mediates the use of social cues about predation risk. Behav-

795 ioral Ecology.(araa151).

796

797 Zuur A, Ieno EN, Walker N, Saveliev AA, Smith GM. 2009. Mixed Effects Models and Extensions in

798 Ecology with R. Springer Science \& Business Media. 


\section{Figure legends}

801 Figure 1: Experimental aims. These schemes present the different hypotheses that we in-

802 vestigated through our experimental design. We hypothesized that relocation would depend

803 on a synthesis of all social information on surrounding habitats. Such use of multiple sources

804 of social information might consist in using an averaged value of multiple information sources

805 (Hyp. 1.a), potentially mediated by focal individual's phenotype (Hyp. 1.b). Conversely, the

806 use of social information could consist in using the contrast between information sources as

807 an indicator of information variability/reliability (Hyp. 1.c). Finally, we hypothesized that the

808 existing contrast between information sources could allow the focal individual to orientate in

809 space in order to join the best of the surrounding habitats (Hyp. 2).

810

811 Figure 2: Joint effects of the fed informant's food intake and the focal individual's state

812 on relocation probability of focal individuals. We looked at the distribution of focal in-

813 dividuals' relocation predicted probability as a function of the fed informant's food intake

814 (number of eaten crickets, standardized values) and the focal individual's state (standardized

815 values). The graph was produced using the Firth's logistic regression results (see Table 3),

816 by plotting the predicted probabilities as a function of the variable of interests' and the inter-

817 cept's coefficients (all other coefficients were fixed to 0, i.e. their average or their baseline

818 level as they are standardized). Black dots display observations from all experimental repli-

819 cates: a dot on the $0 \%$ probability surface corresponds to a focal individual who did not leave

820 his terrarium, a dot on the $100 \%$ probability surface corresponds to a focal individual who

821 left his terrarium. 


\section{Tables}

Table 1: Joint behaviors of the focal individuals and informants.

\begin{tabular}{|c|c|c|c|c|}
\hline Behavior & Description & Unit & $\begin{array}{l}\text { Mean } \\
\text { value }\end{array}$ & Sd \\
\hline Activity & $\begin{array}{l}\text { Cumulative time spent moving by the three individuals } \\
\text { (Aragon et al. } 2006 \text { a., Cote et al. } 2008 \text { a.) }\end{array}$ & Seconds & 949 & 389 \\
\hline Sheltering & $\begin{array}{l}\text { Cumulative time spent sheltering by the three individuals } \\
\qquad \text { (Cote et al. } 2008 \text { a.) }\end{array}$ & Seconds & 1381 & 795 \\
\hline $\begin{array}{l}\text { Escaping } \\
\text { attempt }\end{array}$ & $\begin{array}{l}\text { Time spent by at least one individual trying to escape the } \\
\text { terrarium by scratching or climbing the walls (Aragon et } \\
\qquad \text { al. } 2006 \text { a.) }\end{array}$ & Seconds & 64.8 & 78.6 \\
\hline Boldness & $\begin{array}{l}\text { Time spent by at least by one individual basking above the } \\
\text { shelter (Cote et al. } 2008 \text { b.) }\end{array}$ & Seconds & 177 & 232 \\
\hline $\begin{array}{l}\text { Non-aggressive } \\
\text { proximity }\end{array}$ & $\begin{array}{l}\text { Time spent motionless by at least two individuals in close } \\
\text { proximity to each other, i.e. at a distance less than the } \\
\text { approximate size of an individual (Aragon et al. } 2006 \text { b.) }\end{array}$ & Seconds & 192 & 160 \\
\hline $\begin{array}{l}\text { Competitive } \\
\text { interaction }\end{array}$ & $\begin{array}{l}\text { Number of contacts between two individuals leading to } \\
\text { the flight of at least one individual (Aragon et al. } 2006 \text { b.) }\end{array}$ & $\begin{array}{l}\text { Events } \\
\text { count }\end{array}$ & 3.61 & 3.86 \\
\hline $\begin{array}{l}\text { Tongue- } \\
\text { Flicking }\end{array}$ & $\begin{array}{l}\text { Olfactory cues acquisition that could be interpreted as a } \\
\text { chemical exploration (Cooper 1994, Aragon et al. } 2006 \text { b.) }\end{array}$ & $\begin{array}{l}\text { Events } \\
\text { count }\end{array}$ & 2.88 & 3.43 \\
\hline
\end{tabular}

Description of the joint behaviors of the three juveniles, measured during the last twenty minutes of their confrontation (see Mat\&Met). We did not use cumulative times for escaping attempts and boldness behavior because these behaviors were performed extremely rarely by several individuals at the same time (4\% and $2.7 \%$ respectively). Bibliographic references used to define these metrics are cited in the description column. Mean and standard deviation have been computed over all experimental replicates. 
Table 2: Variables describing the condition of juveniles.

\begin{tabular}{|c|c|c|c|}
\hline Set of variables & $\begin{array}{l}\text { PCA axes (retained for } \\
\text { analysis) }\end{array}$ & Described traits (high contribution variables) & $\begin{array}{l}\text { Explained } \\
\text { variance }\end{array}$ \\
\hline $\begin{array}{l}\text { Joint behaviors } \\
\text { of juveniles }\end{array}$ & Activity level & $\begin{array}{l}\text { Activity }(0.49) \text { / Competitive interaction (0.43) / Non-aggressive } \\
\text { proximity (0.42) / Tongue-flicking (0.38) / Sheltering (-0.44) }\end{array}$ & $50.4 \%$ \\
\hline $\begin{array}{l}\text { Focal } \\
\text { individual's }\end{array}$ & $\begin{array}{l}\text { Morphology of focal } \\
\text { individual's mother }\end{array}$ & $\begin{array}{l}\text { SVL of focal individual's mother }(0.63) \text { / BM of focal individual's } \\
\text { mother }(0.68)\end{array}$ & $41.2 \%$ \\
\hline condition & Focal individual's state & $\begin{array}{l}\text { Focal individual's SVL (0.57) / Focal individual's BM (0.53) / Focal } \\
\text { individual's age (-0.52) }\end{array}$ & $31.3 \%$ \\
\hline \multirow{2}{*}{$\begin{array}{l}\text { Informants' } \\
\text { condition }\end{array}$} & $\begin{array}{l}\text { Morphology of } \\
\text { informants' mothers }\end{array}$ & $\begin{array}{l}\text { SVL of informants' mothers }(0.68) \text { / BM of informants' mothers } \\
\qquad(0.68)\end{array}$ & $39 \%$ \\
\hline & Informants' morphology & Informants' SVL (0.49) / Informants' BM (0.43) & $31.3 \%$ \\
\hline $\begin{array}{l}\text { Contrasts in } \\
\text { informants' }\end{array}$ & $\begin{array}{l}\text { Contrast in morphology of } \\
\text { informants' mothers }\end{array}$ & $\begin{array}{l}\text { Contrast in SVL of informants' mothers (0.62) / Contrast in BM of } \\
\text { informants' mothers }(0.62) \text { / Informants' BM contrast (0.46) }\end{array}$ & $48.6 \%$ \\
\hline condition & $\begin{array}{l}\text { Informants' morphology } \\
\text { contrast }\end{array}$ & Informants' SVL contrasts $(0.83)$ / Informants' BM contrasts $(0.45)$ & $29 \%$ \\
\hline $\begin{array}{l}\text { Differences in } \\
\text { informants }\end{array}$ & $\begin{array}{l}\text { Difference in morphology } \\
\text { of informants' mothers }\end{array}$ & $\begin{array}{c}\text { Difference in SVL of informants' mothers }(0.63) \text { / Difference in BM } \\
\text { of informants' mothers }(0.57)\end{array}$ & $48.5 \%$ \\
\hline condition & $\begin{array}{l}\text { Informants' morphology } \\
\text { difference }\end{array}$ & $\begin{array}{l}\text { Informants' SVL difference (0.59) / Informants' BM difference } \\
(0.60) \text { / Informants' mothers' BM difference }(0.44)\end{array}$ & $37 \%$ \\
\hline
\end{tabular}

This table displays most of the retained variables for statistical analyses (to which must be added the focal individual's sex, informants' sex ratio, and the fed informant's food intake), describing the condition of the focal individual and informants. These variables were obtained by using PCA analyses to synthesize each measured variable set. PCA axes are presented in their order of appearance. Traits with the most important contribution to PCA axes are described, with their loadings displayed in brackets. A positive loading was associated with a positive correlation with the PCA axis and a negative one with a negative correlation. 
Table 3: Selected Firth's logistic regression about focal individuals' relocation probability.

\begin{tabular}{|c|c|c|c|c|c|c|c|}
\hline & Parameter & Coefficient & SE & z-value & df & P-value & $R^{2}$ \\
\hline & Intercept & -0.46 & 0.53 & -0.86 & & 0.39 & \\
\hline & Sex (male) & -1.86 & 0.92 & -2.03 & 1 & $0.043 *$ & 0.21 \\
\hline Focal traits & $\begin{array}{l}\text { Individual's state } \\
\text { (age/morphology) }\end{array}$ & 0.85 & 0.49 & 1.75 & 1 & $0.081^{\bullet}$ & 0.13 \\
\hline \multirow{2}{*}{$\begin{array}{l}\text { Informants' } \\
\text { traits }\end{array}$} & Mothers' morphology & -0.87 & 0.42 & -2.08 & 1 & $0.038 *$ & 0.22 \\
\hline & Fed informant's food intake & -2.26 & 0.77 & -2.96 & 1 & $0.003 * *$ & 0.49 \\
\hline $\begin{array}{l}\text { Focal / } \\
\text { informants }\end{array}$ & Food intake $\mathrm{x}$ focal condition & 1.91 & 0.66 & 2.87 & 1 & $0.004 * *$ & 0.44 \\
\hline interactions & Joint activity level & 1.59 & 0.6 & 2.67 & 1 & $0.008 * *$ & 0.40 \\
\hline
\end{tabular}

Analysis of the selected model (the only one in $\triangle A I C c<2$ ) is displayed here. For each retained variables (see Mat\&Met) we displayed the average coefficient and its standard error. The partial Nagelkerke pseudo-Rsquared $\left(R^{2}\right)$ of each variable in the selected model was also displayed. Wald-tests were performed to test for the significance of each variable effect : we displayed here the associated statistics and p-values. Asterisks indicate the degree of significance. $\cdot: 0.05<\mathrm{p}<0.1, *: 0.01<\mathrm{p}<0.05, * *: 0.001<\mathrm{p}<0.01, * * *: \mathrm{p}<0.001$ 
Table 4: Logistic regression on direction taking (analysis of deviance).

\begin{tabular}{cccc}
\hline \multicolumn{1}{c}{ Parameter } & $\chi^{2}$ & df & P-value \\
\hline \multicolumn{1}{c}{ Fed informant origin } & 0.71 & 1 & 0.4 \\
$\quad$ Sex contrast between informants & 1.88 & 2 & 0.39 \\
Morphologies contrast between informants & 0.004 & 1 & 0.95 \\
Morphologies contrast between informants' mothers & 0.034 & 1 & 0.85 \\
\hline
\end{tabular}

Results of the logistic regression on focal individuals' direction taking are displayed here. An analysis of deviance was performed to test for the significance of each variable effect (likelihood ratio tests). For each test, the chi-squared statistic and the associated p-values are displayed. Asterisks indicate the degree of significance.

• : $0.05<\mathrm{p}<0.1, *: 0.01<\mathrm{p}<0.05, * *: 0.001<\mathrm{p}<0.01, * * *: \mathrm{p}<0.001$ 


\section{Figures}

Figure 1: Experimental aims.

Hyp. 1.a: Social information synthesis (SIS) Use of averaged social information for relocation

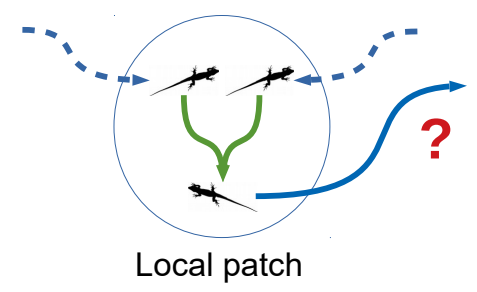

1.c: Contrasted social information (CSI) Use of contrasted social information for relocation

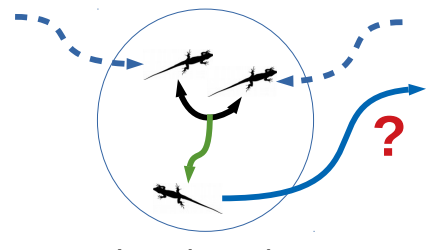

Local patch

1.b: Phenotypic-dependent SIS

Use of averaged social information relatively to focal individual's traits for relocation

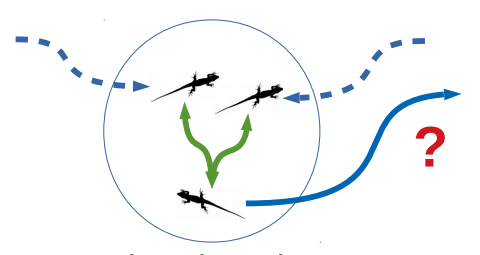

Local patch

\section{2: Spatially CSI}

Use of contrasted social information for orientation

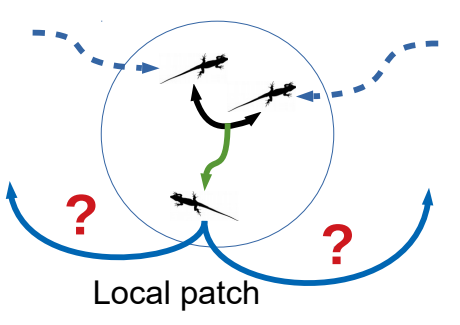

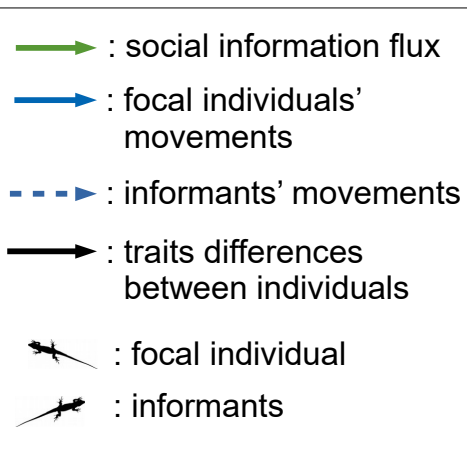


Figure 2: Joint effects of the fed informant's food intake and the focal individual's state on relocation probability of focal individuals.
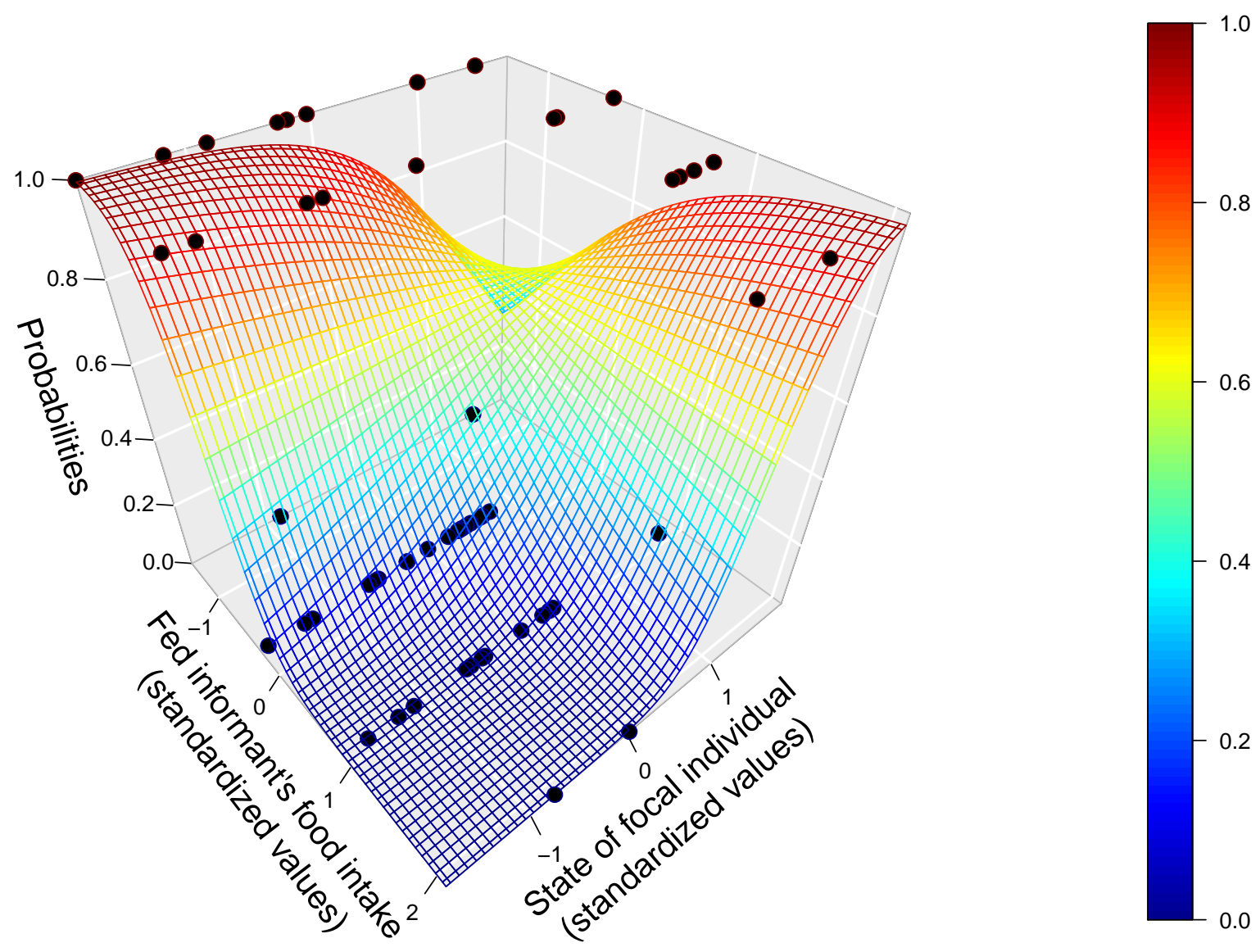